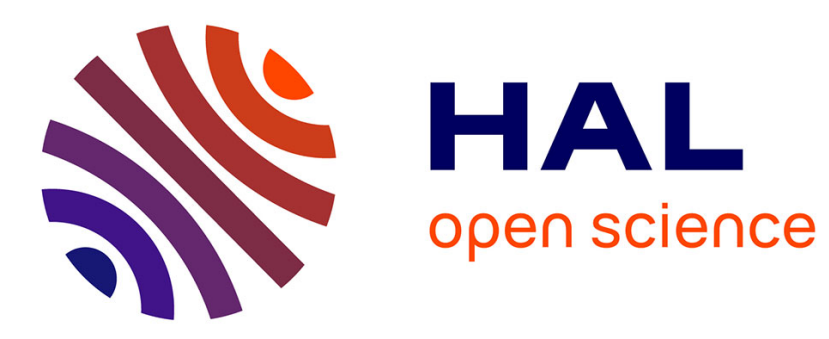

\title{
The high affinity IgE receptor: a signaling update
}

Ulrich Blank, Hua Huang, Toshiaki Kawakami

\section{To cite this version:}

Ulrich Blank, Hua Huang, Toshiaki Kawakami. The high affinity IgE receptor: a signaling update.

Current Opinion in Immunology, 2021, 72, pp.51-58. 10.1016/j.coi.2021.03.015 . hal-03406061

\section{HAL Id: hal-03406061 \\ https://hal.science/hal-03406061}

Submitted on 27 Oct 2021

HAL is a multi-disciplinary open access archive for the deposit and dissemination of scientific research documents, whether they are published or not. The documents may come from teaching and research institutions in France or abroad, or from public or private research centers.
L'archive ouverte pluridisciplinaire HAL, est destinée au dépôt et à la diffusion de documents scientifiques de niveau recherche, publiés ou non, émanant des établissements d'enseignement et de recherche français ou étrangers, des laboratoires publics ou privés. 
The high affinity IgE receptor: a signaling update

by

\section{Ulrich Blank $^{1^{*}}$, Hua Huang ${ }^{2,3}$, and Toshiaki Kawakami ${ }^{4,5}$}

1 Université de Paris, Centre de Recherche sur l'Inflammation, INSERM UMR1149, CNRS ERL8252, Faculté de Médecine site Bichat, Paris, France; Laboratoire d'Excellence Inflamex, Paris, France.

2,Department of Immunology and Genomic Medicine, National Jewish Health, Denver, CO 80206, USA,

${ }^{3}$ Department of Immunology and Microbiology, University of Colorado Anschutz Medical Campus, Aurora, CO 80045, USA

${ }^{4}$ Laboratory of Allergic Diseases, Center for Autoimmunity and Inflammation, La Jolla Institute for Immunology, La Jolla, CA 92037, USA,

${ }^{5}$ Department of Dermatology, School of Medicine, University of California San Diego, La Jolla, CA 92093, USA

\section{*Corresponding author}

Ulrich Blank, Centre de Recherche sur l'Inflammation, INSERM UMR1149, Faculté de Médecine Denis Diderot Université de Paris, 16 Rue Henri Huchard,75780 Paris Cedex 18, France.

e-mail: ulrich.blank@inserm.fr 
Highlights

- Studies with different antigens for the Fc\&RI-bound IgE reveal that differences in affinity, valency and antigen concentration are translated to intracellular signaling events and different outcomes of cell activation.

- Analysis of the secretory machinery of Fc\&RI-induced mast cell degranulation reveal a highly complex machinery regulating involved cytoskeletal reorganization, secretory granule transport mechanisms and fusion.

- Advances made in signaling-dependent cytokine and chemokine gene transcription in response to antigenic stimulation 


\section{Abstract}

Here we update receptor proximal and distant signaling events of the mast cell high affinity IgE receptor (Fc\&RI) launching immediate type I hypersensitivity and an inflammatory cytokine-chemokine cascade. Different physiologic antigen concentrations, their affinity, and valency for the IgE ligand produce distinct intracellular signaling events with different outcomes. Investigating mast cell degranulation has revealed a complex molecular machinery that relays proximal signaling to cytoskeletal reorganization, granule transport and membrane fusion. Several new phosphorylationand calcium-responsive effectors have been described. FcERI signaling also promotes de novo gene transcription. Recent progress has identified enhancers at genes that are upregulated in mast cells after stimulation through FcERI using next generation sequencing methods. Enhancers at genes that respond to antigenic stimulation in human mast cells revealed $\mathrm{Ca}^{+}$-dependency. Stimulationresponsive super enhancers in mouse mast cells have also been identified. Mast cell lineagedependent transcription factor GATA2 primes these enhancers to respond to antigenic stimulation. 


\section{Introduction}

The antigen-dependent aggregation of IgE bound to mast cell (MC) high affinity IgE receptors (FcERI) launches the immediate type I hypersensitivity response and an inflammatory cascade characterized by the exocytosis of secretory granule (SG) content, the de novo synthesis and secretion of prostaglandins/leukotrienes and a diverse set of cytokines/chemokines. Despite unquestionable physiological roles, Fc\&RI-mediated signaling has been largely studied for its implication in allergies. Initially, research focused on receptor-proximal events but recent studies also investigate further downstream pathways. In this review we update the accumulated knowledge on receptor proximal and distant signaling.

\section{Receptor proximal events}

FceRI expressed on MC and basophils consists of $\alpha \beta \gamma_{2}$ heterotetramers of three subunits [1]: The $\alpha$ chain is a type I transmembrane protein that binds the $\operatorname{IgE~Fc}$ portion at a 1:1 ratio, the $\beta$ chain is a receptor-stabilizing and signal-amplifying subunit with four transmembrane domains, and the disulfide-linked dimeric $\gamma$ chains are signal-triggering subunits. $\beta$ and $\gamma$ subunits have an immunoreceptor tyrosine-based activation motif (ITAM). Upon engagement of receptoroccupied IgE by multivalent antigen, tyrosine residues in the ITAMs are phosphorylated by $\beta$ chain-bound Src family protein tyrosine kinase (SFK) Lyn [2]. Phosphorylation of Tyr47/58 residues within $\gamma$-ITAMs recruits another tyrosine kinase Syk via SH2 domain-phosphotyrosine interactions [3]. This activates Syk through conformational changes and tyrosine phosphorylation at multiple sites by autophosphorylation and SFKs to phosphorylate numerous signaling enzymes and adaptors [4]. Syk is essential for most if not all activation events leading to degranulation and de novo synthesis and secretion of lipid mediators, cytokines and chemokines [5,6] (Fig. 1). For example, Syk (and another tyrosine kinase Btk) phosphorylate phospholipase C (PLC)- $\gamma 1$ and $-\gamma 2$ that generate inositol 1,4,5-trisphosphate $\left(\mathrm{IP}_{3}\right)$ and 
diacylglycerol (DAG) from phosphatidylinositol 4,5-bisphosphate $\left(\mathrm{PIP}_{2}\right)$. Diacylglycerol activates protein kinase Cs (PKCs) and IP3 is critically important for $\mathrm{Ca}^{2+}$-release from ER storage sites; $\mathrm{Ca}^{2+}$-depletion from the ER sites is detected by ER $\mathrm{Ca}^{2+}$-sensors STIM-1 and STIM-2, and STIM-1/2 recruitment to plasma membrane $\mathrm{Ca}^{2+}$ channel Orai-1 (calcium releaseactivated channel (CRAC)) leads to activation of the Orail channel and consequent $\mathrm{Ca}^{2+}$ influx into MC [7]. Syk also phosphorylates adaptor proteins, LAT1 and SLP-76 both being required for PLC- $\gamma 1 / 2$ activation (Fig. 1). Another important enzyme is a small family of phosphatidylinositol 3-kinase (PI3K). For activation of PI3K, p85 adaptor subunit of PI3K interacts with the cytosolic adaptor Gab2 after Gab2 phosphorylation by Fyn or Syk [8]. p85bound catalytic subunit $\mathrm{p} 110 \delta$ is essential for antigen-induced anaphylaxis, degranulation and cytokine production [9] (Fig. 1). Analysis of Fyn-deficient MCs also led to the proposal of a Lyn-independent complementary pathway for MC activation [10]. Dynamic complex formation by these adaptors and associated signaling molecules have been covered by excellent reviews $[4,11-13]$.

These signaling events were revealed mostly by using optimal concentration of a highaffinity multivalent antigen in combination with a hapten-specific $\operatorname{IgE}$ (e.g., $\mathrm{DNP}_{20-40}-\mathrm{HSA}$ with anti-DNP IgE). However, different antigen concentrations result in subtle differences in receptor usage of Lyn and other SFKs [14] as well as MAP kinases (MAPKs), with p38 phosphorylation requiring lower receptor occupancy than JNK1 and ERK2 phosphorylation. MAPKs phosphorylation differences are correlated with differential requirement for mRNA expression of cytokines/chemokines [15]. Mobility of IgE-FceRI complexes are slowed to a greater extent by high concentrations than low concentrations of $\mathrm{DNP}_{25}$-BSA and by highervalency than lower-valency antigen [16]. Interestingly, stimulation with low-affinity antigen $\left(2 \mathrm{NP}_{4}-\mathrm{Fab}\right)$ of $\mathrm{IgE}$ anti-DNP sensitized MCs induces less degranulation, leukotriene and cytokine production, but enhanced chemokine production, compared with high-affinity antigen 
(DNP4-Fab) stimulation [17]. Receptor clusters induced by the low-affinity antigen are slower moving and larger in size than those induced by high-affinity antigen. Low-affinity stimulation induces increased Fgr (another SFK) association with FceRI and shifts the signaling from LAT1 to LAT2. Therefore, differences in affinity, valency and concentration of antigen are translated to intracellular signaling events and different outcomes of cell activation [13].

\section{Regulation of receptor-distal events in exocytosis}

\section{Cytoskeletal reorganisation}

FceRI stimulation leads to compound exocytosis releasing virtually all granular content. Such degranulation requires exquisite signal coordination between associated cytoskeletal reorganization and the membrane fusion machinery enabling lipid bilayer mixing. Visible changes in the actin cytoskeleton include cell spreading, lamellar actin ruffling and loss of cortical actin liberating the physical barrier for SG access. Actin reorganization requires $\mathrm{Ca}^{2+}$ influx and is coordinated by the GTPases Rac, RhoA and cdc42 [18,19], downstream targets Wiskott-Aldrich syndrome protein (WASP) promoting actin branching, WASP interacting protein (WIP) and Drebrin (DBN) all of which positively regulate degranulation [19-22]. Experiments with knockout $\mathrm{MC}$ indicate a negative regulatory role for the F-actin binding protein Coronin1A in degranulation. Upon FceRI-stimulation Coronin1A becomes phosphorylated on Ser2, promoting its cytoplasmic relocation and cortex disassembly [23]. Cortical actin also represents a carrier for myosinV actin motors to capture and transport vesicles to fusion sites [24]. These differential functions are explained by a tight coupling to $\mathrm{Ca}^{2+}$ oscillations with SGs being captured at low $\mathrm{Ca}^{2+}$ and high cortical F-actin, followed by vesicle passage through the cortex when $\mathrm{Ca}^{2+}$ levels start to increase and SG fusion occurring at peak levels [25]. Imaging studies showed that SGs fuse at sites where actin dynamics generates circular openings to extrude granular content [26]. 
Long-range SG movement involves a $\mathrm{Ca}^{2+}$-independent $\mathrm{Fyn} / \mathrm{Gab} 2 / \mathrm{RhoA}$ signaling pathway with microtubule formation being blocked in Fyn- and Gab2-deficient cells [18]. Others showed $\mathrm{Ca}^{2+}$-dependency of microtubule nucleation regulated by the association of nucleating $\gamma$-tubulin with $\mathrm{p} 21$-activated kinase interacting exchange factor $\beta(\beta \mathrm{PIX})$, and G protein-coupled receptor kinase-interacting protein (GIT) 1 affecting, respectively, negatively or positively microtubule growth [27]. SG movement towards the plus-end involved the kinesin-1 motor recruited in a PI3K-dependent manner to $\mathrm{Ca}^{2+}$-binding $\mathrm{C} 2$ domain-containing Synaptotagminlike protein3 (Slp3) bound to SG-localized Rab27b GTPase [28] (Fig. 2). The fusion accessory mammalian uncoordinated 18 (Munc18) family member Munc18-2 (STXBP2), besides its role in fusion (see below), also plays a role in microtubule coupling. Localized to SG via the Syntaxin3 (STX3) fusion protein it relocates after stimulation along microtubules into lamellipodia remaining associated with large (fused) SG [29]. Munc18-2 knockdown affected SG collapse into the plasma membrane with SGs appearing stationary docked along microtubules. In parallel, the interaction of Munc18-2 with $\beta$-tubulin decreased suggesting that Munc18-2 dynamically docks SG during microtubular transport [29].

\section{Fusion machinery}

Bilayer mixing in MCs implicates both fusion between SG and with the plasma membrane. It involves the evolutionary conserved N-ethylmaleimide-sensitive factor attachment protein receptor (SNARE) family of proteins (Fig. 2). Composed of target t-SNARES and vesicular vSNARES they form via their $\sim 60$ aa SNARE-helical motifs a fusion-catalyzing tetrameric trans-SNARE complex. The first identified t-SNARE in MCs was SNAP-23. Introduction of blocking Abs into permeabilized MC blocked secretion [30]. During stimulation SNAP-23 relocates from the plasma membrane into forming cytoplasmic degranulation channels, a feature compatible with compound exocytosis. A second t-SNARE identified was STX3, which reversely relocates from SG to the plasma membrane [28,29]. Inhibition of fusion in STX3- 
deficient MCs was partial, whereas no effect was seen in STX4-deficient MC [31]. Some studies found a role of plasma membrane-localized STX4 in degranulation indicating possible compensatory mechanisms [29,32,33]. Concerning v-SNAREs an $\sim 50 \%$ inhibition of degranulation was found in vesicular associated membrane protein8 (VAMP8) knockdown or knockout MCs [34-36]. After stimulation VAMP8 relocates from SGs to the plasma membrane forming enhanced complexes with STX4 and SNAP-23 [35]. VAMP7 and VAMP2 v-SNAREs may additionally contribute [32,37], albeit for the latter no effect was observed in knockout MCs [36]. As VAMP2 formed enhanced complexes with t-SNAREs after stimulation, but only in VAMP8-deficient MC, this may suggest a certain plasticity in SNARE usage [35].

SNARE-complex formation is regulated by phosphorylation. SNAP-23 gets phosphorylated on Ser95/120 enhancing SNARE assembly [38]. This involved IкB kinase 2/ $\beta$ (IKK $\beta 2$ ) [39] albeit this was challenged later [40]. By contrast, phosphorylation of VAMP8 by PKC $\beta$ at the interface for SNARE zippering negatively regulated fusion as supported by phosphomimetic mutants [41]. Regulatory phosphorylation was also demonstrated for STX3 whose constitutive phosphorylation on Thr14 restrains fusion [42], much like STX4 phosphorylation by a Rab3D associated kinase [43]. The STX-binding protein tomosyn-1 (STXBP5) negatively regulates fusion. As knockdown enhances degranulation, it likely blocks productive SNARE complex formation when bound to STX [44]. During stimulation tomosyn-1 becomes phosphorylated on Thr by $\mathrm{PKC} \delta$, inducing its stimulation-dependent dissociation from STX4 and association with STX3. The latter may represent a negative feedback regulatory mechanism.

Several SNARE accessory proteins, some receptive to changes in intracellular $\mathrm{Ca}^{2+}$ levels via their C2-domains, regulate the final docking, priming and fusion steps. According to the neuronal "release of inhibition model" fusion is triggered within milliseconds from a primed state involving a multimeric assembly of $\mathrm{Ca}^{2+}$-sensors [45]. Two neuronal Synaptotagmin 1 (Syt1) molecules interact with a preassembled SNARE prefusion complex stabilized by 
Complexin1 (CPLX1). $\mathrm{Ca}^{2+}$ increases induce a conformational change in Syt1 and CPLX1, which enables SNARE zippering, pulling together opposing membranes further assisted by parallel phospholipid binding of Syt1 that favors membrane curvature. As MC exocytosis does not occur in milliseconds it is likely that the neuronal prefusion complex represents a shortlived intermediate state in MCs. Clearly, MCs use CPLX and Syt isoforms. Absence of the SGlocalized Ca2+-sensor Syt2 and knockdown of CPLX2 markedly inhibited MC secretion $[46,47]$.

Prior to fusion, MC SGs get docked and primed (Fig. 2). Docking involves Munc13-4 a multifunctional effector that interacts via a noncanonical binding motif with Rab27a/b on SGs [48]. TIRF experiments indicated that Rab27a/b-Munc13-4 complexes are necessary to dock motile SG beneath the plasma membrane; docking is lost with interaction-interrupting mutants [48]. Rab27a may additionally function in the short-range actin motility as in knockout MCs degranulation is slightly enhanced [24]. While the phenotype of Rab27a or b-deficient cells was mild, the phenotype of Munc13-4-deficient MCs led to a marked inhibition of degranulation suggesting additional essential functions [24,49]. Evidence from homologous proteins in neuronal cells [45] suggests that Munc13-4 together with Munc18-2 cooperatively promote proper SNARE assembly in the right parallel configuration [49,50] (Fig.2). MC express Doc2 $\alpha$, another $\mathrm{C} 2$ domain-containing protein with $\mathrm{MC}$ degranulation being decreased in $\mathrm{KO} \mathrm{MCs}$ [51]. Doc2 $\alpha$ interacts with SG-localized Munc13-4 [51] and may represent an additional $\mathrm{Ca}^{2+}$ sensor assisting Munc13-4 to fulfill its docking/priming function.

\section{Regulation of signaling-dependent cytokine and chemokine gene transcription in response to antigenic stimulation}

IgE receptor stimulation also promotes de novo gene transcription. Within a few hours, activated MCs secrete a large number of newly synthesized proteins [52,53]. Whole genome 
transcriptome analysis revealed that human skin MCs upregulated 260 and downregulated 84 genes after stimulation through FceRI for two hours [54]. Mouse MC upregulated 1089 genes, and downregulated 280 genes [55]. The upregulated genes are significantly enriched in gene sets that encode signaling molecules, transcription factors, proteases and other enzymes, cell surface molecules, and cytokines/chemokines. Whereas the down regulated genes are significantly enriched in sets involved in cell proliferation, signal transduction, apoptosis or enriched in genes encoding receptors [55].

How genes detect the proximal signals triggered by antigenic stimulation is not completely understood. A number of transcription factors (TFs) are activated through phosphorylation modification after antigenic stimulation. These TFs are called signal-dependent TFs (SDTFs). SDTFs STAT5, NFAT, AP1, NFkb and EGR2 are critical in FceRI-upregulated gene expression [56]. Our knowledge of enhancer locations to which SDTFs bind in response to antigenic stimulation is still limited. Enhancers are segments of DNA located in the non-coding regions of genes. They activate gene transcription by delivering important accessory factors to the promoter [57-59]. It is generally believed that binding of the SDTFs to enhancers activates them [60]. Activated enhancers then interact with other enhancers to form loops with promoters by bringing transcription factors and coactivators together with basic transcriptional complexes. Binding of SDTFs, other TFs and co-factors to enhancers also creates accessible regions within enhancers and recruit histone modifying enzymes to add acetyl or methyl groups to histones. Histone modifications can be used to identify potential enhancers [60]. For example, the poised enhancers can be identified by monomethylation of lysine residue 4 on histone 3 (H3K4me1) and active enhancers can be marked by acetylation of lysine residue 27 on histone 3 (H3K27ac) modification [61-64]. The accessible regions can be located by ATAC-seq [65].

A recent study used the next generation sequencing method to examine enhancers that can respond to antigenic or IL-33 stimulation and found that $\mathrm{Ca} 2^{+}$-dependent open chromatin 
(COC) domains within enhancers in human blood-derived MCs in response to FceRI or IL-33

stimulation [66]. TF binding motif analysis revealed enrichment of ATF3, BATF and AP1binding sites in COC domains (Fig. 3). Whether ATF3, BATF and AP-1 indeed play a critical role in promoting gene transcription in response to FceRI-crosslinking awaits further experiments that knockout or knockdown ATF3, BATF and AP-1 expression in MCs. Recent data show that GATA2 binds to super-enhancers in resting mouse MCs prior to FceRIstimulation. Deletion of the Gata2 gene in mouse MCs abolished the upregulation of gene transcription in response to $\operatorname{IgE}$ receptor crosslinking, suggesting that GATA2 is essential in recruiting SDTFs to FceRI-induced enhancers [55]. TF binding motif analysis revealed that GATA2, EGR2 and AP1-binding sites are enriched in the FceRI crosslinking-induced enhancers (Fig 3). Further experiments are underway to examine the role of EGR2 and AP1 in promoting FceRI-induced gene transcription. We also found that FceRI-induced enhancers can cooperate with constitutively active enhancers to generate maximal gene transcription (Fig 3 ) [67].

\section{Figures legends}

Figure 1. FceRI signaling pathways that lead to degranulation and de novo synthesis of eicosanoids, cytokines and chemokines. Aggregation of IgE-occupied FceRI induces activation of the SFK Lyn, which phosphorylates tyrosine residues of ITAM motifs (indicated yellow rectangles) of $\beta$ and $\gamma$ chains. Syk is recruited to the phosphorylated $\gamma$ chains. Activation of Syk leads to phosphorylation of LAT1 and LAT2. These proteins serve as scaffolds for multimolecular signaling complexes for the binding of adaptor molecules such as Gads, Grb2, SLP-76 and Shc; guanosine triphosphate exchangers such as Sos and Vav; and the enzymes, PLC- $\gamma 2$ and PLC- $\gamma 1$. PLC- $\gamma$ catalyzes the hydrolysis of PIP 2 to DAG and $\mathrm{IP}_{3}$, which results in the activation of PKCs and the release of intracellular $\mathrm{Ca}^{2+}$, respectively. These signals lead to degranulation. Phosphatidylinositol 3-kinase (PI3K) is activated when its adaptor subunit $\mathrm{p} 85$ is bound by Gab2 phosphorylated by Fyn or/and Syk. The generation of phosphatidylinositol 3,4,5-trisphosphate $\left(\mathrm{PIP}_{3}\right)$ by $\mathrm{PI} 3 \mathrm{~K}$ p110 $\delta$ catalytic subunit leads to the recruitment of $\mathrm{PH}$ domain-containing molecules such as Btk, PDK1, and Akt. Sos- and Vav-regulated GDP-GTP exchange of Ras, Rac and Rho leads to the activation of MAPK cascades. Erk signaling regulates phospholipase $\mathrm{A}_{2}$ activation, leading to the generation of eicosanoids. Increased $\mathrm{Ca}^{2+}$ concentration activates $\mathrm{Ca}^{2+} /$ calmodulin-dependent serine phosphatase calcieurin. Calcineurin dephosphorylates NFAT and allow it to translocate into the nucleus. Fe\&RI stimulation leads to 
degradation of $\mathrm{I} \kappa \mathrm{B}$ and allows nuclear localization of NF- $\kappa \mathrm{B}$. These transcription factors regulate the transcription of cytokines and other proinflammatory factors.

Figure 2. The SG transport and fusion machinery in mast cells. For reason of simplicity the docking and fusion steps are detailed only at the PM. Note however, that in MC fusion between SG is part of the compound exocytosis process during which relevant actors redistribute to the plasma membrane and inversely to the SGs. Long-range transport towards the plus-end of microtubules involves the kinesin-1 motor recruited in a PI3K-dependent manner to Synaptotagmin-like protein 3 (Slp3) (containing $\mathrm{Ca}^{2+}$-binding $\mathrm{C} 2$ domains) that binds via its Slp homology domain (SHD) domain to the SG-localized Rab27b GTPase. The fusion promoting protein Munc18-2 also participates in the interaction with $\beta$-tubulin via a so far unknown effector. When reaching the plasma membrane actin disassembly (not shown) allows docking of SG at the plasma membrane involving several fusion accessory proteins such as Munc13-4 bound to Rab27a/b assisted by Doc2 some of which contain Ca2+/phospholipid binding $\mathrm{C} 2$ domains. This allows fusion priming and loose SNARE-zippering, which in MC likely represents a short-lived intermediate state (not depicted) followed by the assembly of the stable trans-SNARE complex that drives membrane bilayer mixing and is triggered at high $\mathrm{Ca} 2+$ concentration by conformational rearrangements of C2-domain containing Syt 2 and CPLX2 and the coordinated action of Munc18-2 and Munc13-4 that coordinate the correct assembly of the SNARE complex.

Fig 3. The induced enhancers detect signals and cooperate with constitutively active enhancers to promote gene transcription. Signal-dependent transcription factors are activated through phosphorylation by kinases that are activated by aggregation of FceRI bound with IgE and their cognate antigens. These TFs, such as pAP-1, pEGR2, pATF3 and pBATF bind to the consensus DNA binging motifs in the antigenic stimulation-induced enhancers to activate the induced enhancers, which then interact with constitutively active enhancers, forming a higher order of transcriptional complex with promoters to promote gene transcription in response to antigenic stimulation. TF, transcription factor; MLL3/4, histone-lysine Nmethyltransferase, H3 lysine-4 specific; P300, histone acetyltransferase p300; Pol II, RNA polymerase II; $p$, phosphorylation. Green dot, monomethylation of lysine residue 4 on histone 3 (H3K4me1); red dot, acetylation of lysine residue 27 on histone 3 (H3K27ac) modification.

\section{Acknowledgements}

T. Kawakami is supported by grants from the US National Institutes of Health (Al124734 and Al146042). H. Huang is supported by grants from the National Institutes of Health R01Al107022 and R01Al135194. H. Huang thanks Ms. Katherine Rauch for assisting in figure preparation. U. Blank is supported by Inserm, CNRS, University of Paris and by the "Equipe program" of the Fondation pour la recherche médicale (FRM). Work of U. Blank is also supported by the Investissements d'Avenir program grants ANR-11-IDEX-0005-02, Sorbonne Paris Cite, Laboratoire d'excellence INFLAMEX and ANR-19-CE15-0016 IDEA.

\section{Conflict of interest statement:}

All authors declare that the do not have any conflict of interest. 
References and recommended readings

1. Kinet JP: The high-affinity IgE receptor (Fc epsilon RI): from physiology to pathology. Annu Rev Immunol 1999, 17:931-972.

2. Pribluda VS, Pribluda C, Metzger H: Transphosphorylation as the mechanism by which the high-affinity receptor for IgE is phosphorylated upon aggregation. Proc Natl Acad Sci U S A 1994, 91:11246-11250.

3. Paolini R, Jouvin MH, Kinet JP: Phosphorylation and dephosphorylation of the highaffinity receptor for immunoglobulin $\mathrm{E}$ immediately after receptor engagement and disengagement. Nature 1991, 353:855-858.

4. Siraganian RP, de Castro RO, Barbu EA, Zhang J: Mast cell signaling: the role of protein tyrosine kinase Syk, its activation and screening methods for new pathway participants. FEBS Lett 2010, 584:4933-4940.

5. Costello PS, Turner M, Walters AE, Cunningham CN, Bauer PH, Downward J, Tybulewicz VL: Critical role for the tyrosine kinase Syk in signalling through the high affinity IgE receptor of mast cells. Oncogene 1996, 13:2595-2605.

6. Zhang J, Berenstein EH, Evans RL, Siraganian RP: Transfection of Syk protein tyrosine kinase reconstitutes high affinity IgE receptor-mediated degranulation in a Syknegative variant of rat basophilic leukemia RBL-2H3 cells. J Exp Med 1996, 184:7179.

7. Ma HT, Beaven MA: Regulation of Ca2+ signaling with particular focus on mast cells. Crit Rev Immunol 2009, 29:155-186.

8. Yu M, Lowell CA, Neel BG, Gu H: Scaffolding adapter Grb2-associated binder 2 requires Syk to transmit signals from FcepsilonRI. J Immunol 2006, 176:2421-2429.

9. Ali K, Bilancio A, Thomas M, Pearce W, Gilfillan AM, Tkaczyk C, Kuehn N, Gray A, Giddings $J$, Peskett $E$, et al.: Essential role for the p110delta phosphoinositide 3-kinase in the allergic response. Nature 2004, 431:1007-1011.

10. Parravicini V, Gadina M, Kovarova M, Odom S, Gonzalez-Espinosa C, Furumoto Y, Saitoh $\mathrm{S}$, Samelson LE, O'Shea JJ, Rivera J: Fyn kinase initiates complementary signals required for IgE-dependent mast cell degranulation. Nat Immunol 2002, 3:741-748.

11. Kambayashi T, Koretzky GA: Proximal signaling events in Fc epsilon RI-mediated mast cell activation. J Allergy Clin Immunol 2007, 119:544-552; quiz 553-544.

12. Metcalfe DD, Peavy RD, Gilfillan AM: Mechanisms of mast cell signaling in anaphylaxis. J Allergy Clin Immunol 2009, 124:639-646; quiz 647-638.

13. Suzuki R: The Emerging Picture of Mast Cell Activation: The Complex Regulatory Network of High-Affinity Receptor for Immunoglobulin E Signaling. Biol Pharm Bull 2017, 40:1828-1832.

14. Xiao W, Nishimoto $H$, Hong $H$, Kitaura J, Nunomura S, Maeda-Yamamoto M, Kawakami $Y$, Lowell CA, Ra C, Kawakami T: Positive and negative regulation of mast cell activation by Lyn via the FcepsilonRI. J Immunol 2005, 175:6885-6892.

15. Gonzalez-Espinosa C, Odom S, Olivera A, Hobson JP, Martinez ME, Oliveira-Dos-Santos A, Barra L, Spiegel S, Penninger JM, Rivera J: Preferential signaling and induction of allergy-promoting lymphokines upon weak stimulation of the high affinity IgE receptor on mast cells. J Exp Med 2003, 197:1453-1465. 
16. Andrews NL, Pfeiffer JR, Martinez AM, Haaland DM, Davis RW, Kawakami T, Oliver JM, Wilson BS, Lidke DS: Small, mobile FcepsilonRI receptor aggregates are signaling competent. Immunity 2009, 31:469-479.

17. Suzuki R, Leach S, Liu W, Ralston E, Scheffel J, Zhang W, Lowell CA, Rivera J: Molecular editing of cellular responses by the high-affinity receptor for IgE. Science 2014, 343:1021-1025.

.. Study showing that affinity of antigen to IgE is translated to different in vitro and in vivo outcomes of FceRI signaling.

18. Nishida K, Yamasaki S, Ito Y, Kabu K, Hattori K, Tezuka T, Nishizumi H, Kitamura D, Goitsuka R, Geha RS, et al.: Fc\{epsilon\}RI-mediated mast cell degranulation requires calcium-independent microtubule-dependent translocation of granules to the plasma membrane. J Cell Biol 2005, 170:115-126.

19. Draber $\mathrm{P}$, Sulimenko V, Draberova E: Cytoskeleton in mast cell signaling. Front Immunol 2012, 3:130.

20. Pivniouk VI, Snapper SB, Kettner A, Alenius H, Laouini D, Falet $H$, Hartwig J, Alt FW, Geha RS: Impaired signaling via the high-affinity IgE receptor in Wiskott-Aldrich syndrome protein-deficient mast cells. Int Immunol 2003, 15:1431-1440.

21. Kettner A, Kumar L, Anton IM, Sasahara Y, de la Fuente M, Pivniouk VI, Falet H, Hartwig $\mathrm{JH}$, Geha RS: WIP regulates signaling via the high affinity receptor for immunoglobulin E in mast cells. J Exp Med 2004, 199:357-368.

22. Law M, Lee $Y$, Morales JL, Ning G, Huang W, Pabon J, Kannan AK, Jeong AR, Wood A, Carter $C$, et al.: Cutting Edge: Drebrin-Regulated Actin Dynamics Regulate IgEDependent Mast Cell Activation and Allergic Responses. J Immunol 2015, 195:426430.

23. Foger $\mathrm{N}$, Jenckel A, Orinska Z, Lee KH, Chan AC, Bulfone-Paus S: Differential regulation of mast cell degranulation versus cytokine secretion by the actin regulatory proteins Coronin1a and Coronin1b. J Exp Med 2011, 208:1777-1787.

24. Singh RK, Mizuno K, Wasmeier C, Wavre-Shapton ST, Recchi C, Catz SD, Futter C, Tolmachova T, Hume AN, Seabra MC: Distinct and opposing roles for Rab27a/Mlph/MyoVa and Rab27b/Munc13-4 in mast cell secretion. FEBS J 2013, 280:892-903.

25. Wollman R, Meyer T: Coordinated oscillations in cortical actin and Ca2+ correlate with cycles of vesicle secretion. Nat Cell Biol 2012, 14:1261-1269.

.. Study showing that cytoskeletal reorganization necessary for degranulation is tightly coupled to $\mathrm{Ca}^{2+}$ oscillations. SGs are captured at high cortical F-actin and low $\mathrm{Ca}^{2+}$ followed by vesicle passage through the cortex with increasing $\mathrm{Ca}^{2+}$ levels and SG fusion occurring at peak levels

26. Colin-York H, Li D, Korobchevskaya K, Chang VT, Betzig E, Eggeling C, Fritzsche M: Cytoskeletal actin patterns shape mast cell activation. Commun Biol 2019, 2:93.

27. Sulimenko V, Hajkova Z, Cernohorska M, Sulimenko T, Sladkova V, Draberova L, Vinopal $S$, Draberova E, Draber P: Microtubule nucleation in mouse bone marrow-derived mast cells is regulated by the concerted action of GIT1/betaPIX proteins and calcium. J Immunol 2015, 194:4099-4111.

28. Munoz I, Danelli L, Claver J, Goudin N, Kurowska M, Madera-Salcedo IK, Huang JD, Fischer A, Gonzalez-Espinosa C, de Saint Basile G, et al.: Kinesin-1 controls mast cell degranulation and anaphylaxis through PI3K-dependent recruitment to the granular SIp3/Rab27b complex. J Cell Biol 2016, 215:203-216. 
.. $\quad$ Study indicating that long-range SG transport involves kinesin-1 that gets coupled to SG via a SLP3/Rab27b complex in a PI3Kinase-dependent manner.

29. Brochetta C, Suzuki R, Vita F, Soranzo MR, Claver J, Madjene LC, Attout T, Vitte J, VarinBlank N, Zabucchi G, et al.: Munc18-2 and syntaxin 3 control distinct essential steps in mast cell degranulation. $J$ Immunol 2014, 192:41-51.

30. Guo Z, Turner C, Castle D: Relocation of the t-SNARE SNAP-23 from lamellipodia-like cell surface projections regulates compound exocytosis in mast cells. Cell 1998, 94:537548.

31. Sanchez E, Gonzalez EA, Moreno DS, Cardenas RA, Ramos MA, Davalos AJ, Manllo J, Rodarte Al, Petrova Y, Moreira DC, et al.: Syntaxin 3, but not syntaxin 4, is required for mast cell-regulated exocytosis, where it plays a primary role mediating compound exocytosis. J Biol Chem 2019, 294:3012-3023.

32. Woska JR, Jr., Gillespie ME: Small-interfering RNA-mediated identification and regulation of the ternary SNARE complex mediating RBL-2H3 mast cell degranulation. Scand J Immunol 2011, 73:8-17.

33. Yang Y, Kong B, Jung Y, Park JB, Oh JM, Hwang J, Cho JY, Kweon DH: Soluble NEthylmaleimide-Sensitive Factor Attachment Protein Receptor-Derived Peptides for Regulation of Mast Cell Degranulation. Front Immunol 2018, 9:725.

34. Lippert U, Ferrari DM, Jahn R: Endobrevin/VAMP8 mediates exocytotic release of hexosaminidase from rat basophilic leukaemia cells. FEBS Lett 2007, 581:3479-3484.

35. Tiwari N, Wang CC, Brochetta C, Ke G, Vita F, Qi Z, Rivera J, Soranzo MR, Zabucchi G, Hong W, et al.: VAMP-8 segregates mast cell-preformed mediator exocytosis from cytokine trafficking pathways. Blood 2008, 111:3665-3674.

36. Puri N, Roche PA: Mast cells possess distinct secretory granule subsets whose exocytosis is regulated by different SNARE isoforms. Proc Natl Acad Sci U S A 2008, 105:2580-2585.

37. Sander LE, Frank SP, Bolat S, Blank U, Galli T, Bigalke H, Bischoff SC, Lorentz A: Vesicle associated membrane protein (VAMP)-7 and VAMP-8, but not VAMP-2 or VAMP-3, are required for activation-induced degranulation of mature human mast cells. Eur J Immunol 2008, 38:855-863.

38. Hepp R, Puri N, Hohenstein AC, Crawford GL, Whiteheart SW, Roche PA:

Phosphorylation of SNAP-23 regulates exocytosis from mast cells. J Biol Chem 2005, 280:6610-6620.

39. Suzuki K, Verma IM: Phosphorylation of SNAP-23 by IkappaB kinase 2 regulates mast cell degranulation. Cell 2008, 134:485-495.

40. Peschke K, Weitzmann A, Heger K, Behrendt R, Schubert N, Scholten J, Voehringer D, Hartmann K, Dudeck A, Schmidt-Supprian M, et al.: IkappaB kinase $\mathbf{2}$ is essential for IgE-induced mast cell de novo cytokine production but not for degranulation. Cell Rep 2014, 8:1300-1307.

41. Malmersjo S, Di Palma S, Diao J, Lai Y, Pfuetzner RA, Wang AL, McMahon MA, Hayer A, Porteus $M$, Bodenmiller $B$, et al.: Phosphorylation of residues inside the SNARE complex suppresses secretory vesicle fusion. EMBO J 2016, 35:1810-1821.

42. Tadokoro S, Shibata T, Inoh Y, Amano T, Nakanishi M, Hirashima N, Utsunomiya-Tate N: Phosphorylation of syntaxin-3 at Thr 14 negatively regulates exocytosis in RBL-2H3 mast cells. Cell Biol Int 2016, 40:589-596. 
43. Pombo I, Martin-Verdeaux S, Iannascoli B, Le Mao J, Deriano L, Rivera J, Blank U: IgE receptor type I-dependent regulation of a Rab3D-associated kinase. A possible link in the calcium-dependent assembly of SNARE complexes. J Biol Chem 2001, 12:12.

44. Madera-Salcedo IK, Danelli L, Tiwari N, Dema B, Pacreau E, Vibhushan S, Birnbaum J, Agabriel C, Liabeuf V, Klingebiel C, et al.: Tomosyn functions as a PKCdelta-regulated fusion clamp in mast cell degranulation. Sci Signal 2018, 11.

.. Study showing that the STX-binding protein tomosyn-1 (STXBP5) regulates the availability of fusion-competent STX proteins. STX-binding of tomosyn-1 is regulated by Thr phosphorylation by PKC $\delta$.

45. Brunger AT, Choi UB, Lai Y, Leitz J, White KI, Zhou Q: The pre-synaptic fusion machinery. Curr Opin Struct Biol 2019, 54:179-188.

46. Tadokoro S, Nakanishi M, Hirashima N: Complexin II facilitates exocytotic release in mast cells by enhancing Ca2+ sensitivity of the fusion process. J Cell Sci 2005, 118:2239-2246.

47. Melicoff E, Sansores-Garcia L, Gomez A, Moreira DC, Datta P, Thakur P, Petrova Y, Siddiqi T, Murthy JN, Dickey BF, et al.: Synaptotagmin-2 controls regulated exocytosis but not other secretory responses of mast cells. J Biol Chem 2009, 284:19445-19451.

48. Elstak ED, Neeft M, Nehme NT, Voortman J, Cheung M, Goodarzifard M, Gerritsen HC, van Bergen En Henegouwen PM, Callebaut I, de Saint Basile G, et al.: The munc13-4rab27 complex is specifically required for tethering secretory lysosomes at the plasma membrane. Blood 2011, 118:1570-1578.

49. Rodarte EM, Ramos MA, Davalos AJ, Moreira DC, Moreno DS, Cardenas El, Rodarte Al, Petrova $Y$, Molina S, Rendon LE, et al.: Munc13 proteins control regulated exocytosis in mast cells. J Biol Chem 2018, 293:345-358.

50. Gutierrez BA, Chavez MA, Rodarte Al, Ramos MA, Dominguez A, Petrova Y, Davalos AJ, Costa RM, Elizondo R, Tuvim MJ, et al.: Munc18-2, but not Munc18-1 or Munc18-3, controls compound and single-vesicle-regulated exocytosis in mast cells. J Biol Chem 2018, 293:7148-7159.

- Complete analysis of all Munc18 isoforms in knockout models show that it is the Munc18-2 isoform, which is the relevant SNARE accessory protein in mast cells

51. Higashio H, Nishimura N, Ishizaki H, Miyoshi J, Orita S, Sakane A, Sasaki T: Doc2 alpha and Munc13-4 regulate $\mathrm{Ca}(2+)$-dependent secretory lysosome exocytosis in mast cells. J Immunol 2008, 180:4774-4784.

52. Mukai K, Tsai M, Saito H, Galli SJ: Mast cells as sources of cytokines, chemokines, and growth factors. Immunol Rev 2018, 282:121-150.

53. Draber P, Halova I, Polakovicova I, Kawakami T: Signal transduction and chemotaxis in mast cells. Eur J Pharmacol 2016, 778:11-23.

54. Motakis E, Guhl S, Ishizu Y, Itoh M, Kawaji H, de Hoon M, Lassmann T, Carninci P, Hayashizaki $Y$, Zuberbier $T$, et al.: Redefinition of the human mast cell transcriptome by deep-CAGE sequencing. Blood 2014, 123:e58-67.

55. Li Y, Gao J, Kamran M, Harmacek L, Danhorn T, Leach SM, O'Connor BP, Hagman JR, Huang $\mathrm{H}$ : GATA2 regulates mast cell identity and responsiveness to antigenic stimulation by promoting chromatin remodeling at super-enhancers. Nat Commun 2021, 12:494.

.. This paper demonstrates that GATA2 promotes chromatin accessibility at the superenhancers of MC mast cell identity genes and primes both typical and super-enhancers at genes that respond to antigenic stimulation in mouse mast cells. 
56. Cildir G, Pant H, Lopez AF, Tergaonkar V: The transcriptional program, functional heterogeneity, and clinical targeting of mast cells. J Exp Med 2017, 214:2491-2506.

57. Schaffner W: Enhancers, enhancers - from their discovery to today's universe of transcription enhancers. Biol Chem 2015, 396:311-327.

58. Schoenfelder S, Fraser P: Long-range enhancer-promoter contacts in gene expression control. Nat Rev Genet 2019, 20:437-455.

59. Spitz F, Furlong EE: Transcription factors: from enhancer binding to developmental control. Nat Rev Genet 2012, 13:613-626.

60. Rosenfeld MG, Lunyak VV, Glass CK: Sensors and signals: a coactivator/corepressor/epigenetic code for integrating signal-dependent programs of transcriptional response. Genes Dev 2006, 20:1405-1428.

61. Calo E, Wysocka J: Modification of enhancer chromatin: what, how, and why? Mol Cell 2013, 49:825-837.

62. Creyghton MP, Cheng AW, Welstead GG, Kooistra T, Carey BW, Steine EJ, Hanna J, Lodato MA, Frampton GM, Sharp PA, et al.: Histone H3K27ac separates active from poised enhancers and predicts developmental state. Proc Natl Acad Sci U S A 2010, 107:21931-21936.

63. Heintzman ND, Stuart RK, Hon G, Fu Y, Ching CW, Hawkins RD, Barrera LO, Van Calcar S, Qu C, Ching KA, et al.: Distinct and predictive chromatin signatures of transcriptional promoters and enhancers in the human genome. Nat Genet 2007, 39:311-318.

64. Rada-Iglesias A, Bajpai R, Swigut T, Brugmann SA, Flynn RA, Wysocka J: A unique chromatin signature uncovers early developmental enhancers in humans. Nature 2011, 470:279-283.

65. Corces MR, Trevino AE, Hamilton EG, Greenside PG, Sinnott-Armstrong NA, Vesuna S, Satpathy AT, Rubin AJ, Montine KS, Wu B, et al.: An improved ATAC-seq protocol reduces background and enables interrogation of frozen tissues. Nat Methods 2017, 14:959-962.

66. Cildir G, Toubia J, Yip KH, Zhou M, Pant H, Hissaria P, Zhang J, Hong W, Robinson N, Grimbaldeston MA, et al.: Genome-wide Analyses of Chromatin State in Human Mast Cells Reveal Molecular Drivers and Mediators of Allergic and Inflammatory Diseases. Immunity 2019, 51:949-965 e946.

.. $\quad$ this paper describes that antigenic stimulation induces formation of new enhancers that depend on $\mathrm{Ca} 2+$ signaling in human mast cells.

67. Kamran M, Liang J, Liu B, Li Y, Gao J, Keating A, Mohamed F, Dai S, Reinhardt R, Jiong Y, et al.: The Clusters of Transcription Factors NFATC2, STAT5, GATA2, AP1, RUNX1 and EGR2 Binding Sites at the Induced II13 Enhancers Mediate II13 Gene Transcription in Response to Antigenic Stimulation. J Immunol 2020, 205:33113318. 


\section{Conflict of interest statement:}

All authors declare that the do not have any conflict of interest. 


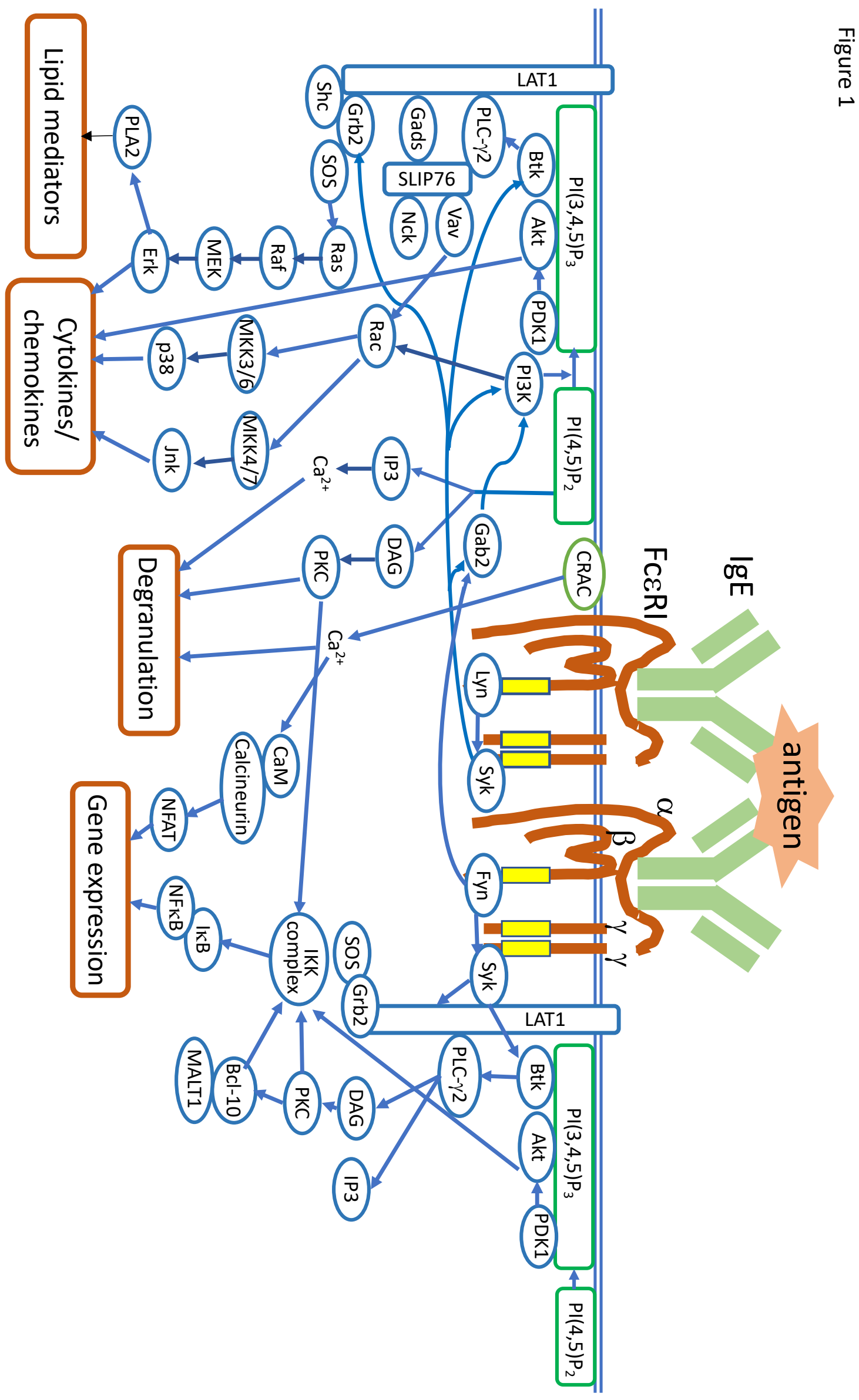




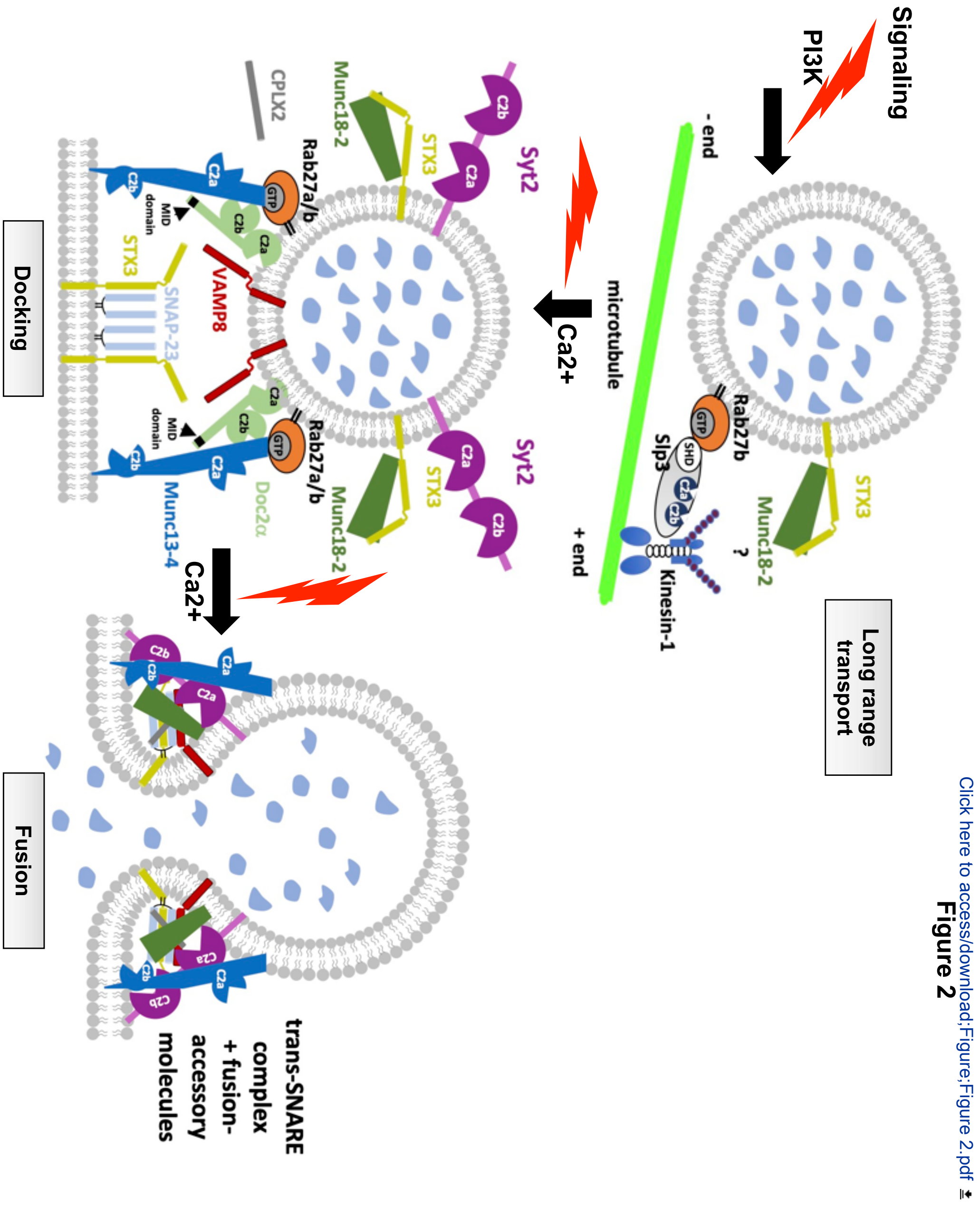




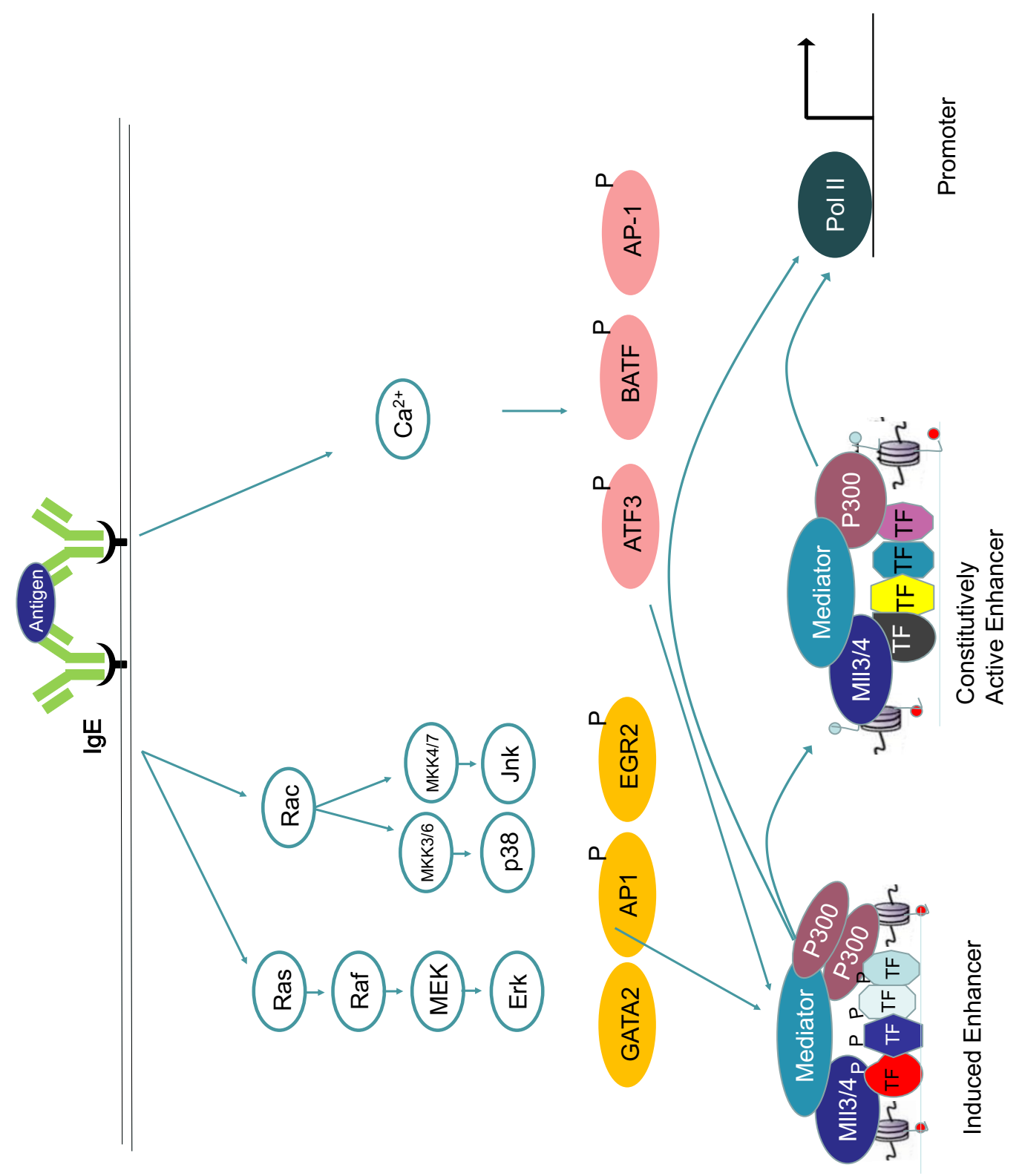

